\title{
Mass Customization of Education by an Institution of HE: What Can We Learn from Industry?
}

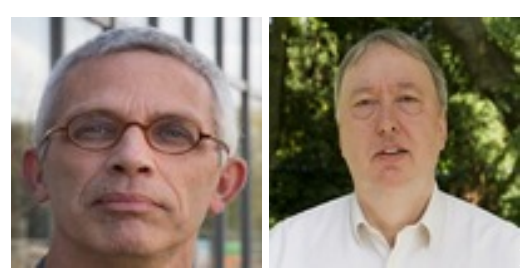

Robert Schuwer and Rob Kusters

Open Universiteit, Netherlands

\section{Abstract}

One of the claims the OER movement makes is that availability of (open) digital learning materials improves the quality of education. The promise is the ability to offer educational programs that take into account specific demands of the learner. The question is how to reach a situation where a customized demand can be met using OER with acceptable quality against acceptable costs. This situation resembles mass customization as is common in industry for several decades now. Techniques from an industry where an end product is assembled with the demands of the customer as a starting point can be translated to the field of education where courses and learning paths through a curriculum are assembled using a mixture of open and closed learning materials and learning services offered by an institution. Advanced IT support for both the modeling of the learning materials and services and a configurator to be used by a learner are necessary conditions for this approach.

Keywords: Mass customization; personalized learning; OER 


\section{Introduction}

The launch of the MIT OpenCourseware project in 2001 marked the beginning of worldwide publishing of open educational resources (OER). This development aims at achieving high availability of learning materials with the possibilities to adapt these to fit to their context of use. One of the claims the OER movement makes is that availability of (open) digital learning materials improves the quality of education (Hodgkinson-Williams, 2010; Commonwealth of Learning, 2011). The promise is the ability to offer educational programs that take into account specific demands of the learner. This promise is heard even louder since the rise of the MOOCs in 2012 (Horn \& Christensen, 2013). This trend highlights the unbundling of education, where learning, certifying of learning, and degree-awarding does not have to be offered by one single university. A consequence of this trend is the availability of more learning pathways than before, not all necessarily leading to a degree. A learner will be able to shop to fulfill his demand, thereby challenging universities to satisfy this demand. Personal circumstances (e.g., job demands, financial situation) can create a demand for alternative learning paths.

Bates (2005) noted that student diversity within the technological era has to be considered also:
Learners are not a homogenous mass, but vary considerably in terms of educational background, income, age and learning experience. This diversity of the student body is growing fast. It will become increasingly important for educational organizations to be able to deliver their teaching in a variety of technological formats, depending on the needs of the individual, the teaching context, and the target groups to be reached. (p. 211)

One can expect this demand for more individualized learning paths to grow over the coming years, because of the increasing need for people with a higher education and because of the current financial crisis. The former means that other people than youngsters are needed to fulfill the demand. The latter is the cause of budget cuts for universities and student loans, forcing more students to take a job in addition to their study activities.

OER can be considered as generic building blocks from which to create learning materials fit for a learner or a homogeneous group of learners. A more common name for those building blocks is learning objects (Neven \& Duval, 2002). Nowadays, creating these learning materials requires a lot of craftsmanship and effort, which results in different levels of quality and high associated costs. 
Publishing and reusing OER poses several challenges (Schuwer, 2013; Yuen \& Wong, 2013):

- findability of suitable OER;

- dealing with different technical formats that hinders combining the building blocks into one overall layout;

- indistinctness about underlying didactical approaches and necessary prerequisites;

- determining if the quality of the OER is sufficient;

- incompatible or even the absence of open licenses;

- fear over copyright infringement, ownership and legal barriers other than copyright;

- business models to create a sustainable ecosystem of OER;

- human factors - resistance against sharing or reuse because of lack of reward and recognition, possible negative impact on reputation, and lack of support.

Adapting OER and localizing it to the context in which it is used is an important activity for reuse (Matkin, 2009). Unfortunately, this can be a difficult and expensive process (OECD, 2007, p. 60).

So the question is how to reach a situation where a customized demand can be met using OER with acceptable quality against acceptable costs, taking into account the challenges as listed above.

In this paper we will address the applicability and added value of assemble to order (ATO) to answer this question. ATO is an approach developed in industry to combine the advantage of customization (which provides customer specific, but usually very expensive products) with mass production (which produces a standard product of acceptable quality for a low price). ATO functions by developing a limited number of components and combining these, so a large array of different products can be assembled. Such an approach will provide variety and quality for an acceptable price.

ATO is an approach to realize mass customization. In Tseng and Jiao (2001) mass customization is defined as "The technologies and systems to deliver goods and services that meet individual customers' needs with near mass production efficiency". For education, this is not equivalent to personalized learning. In Wikipedia ${ }^{1}$, personalized learning is defined as "the tailoring of pedagogy, curriculum and learning environments to meet the needs and aspirations of individual learners." According to the U.S.

\footnotetext{
${ }^{1}$ http://en.wikipedia.org/wiki/Personalized_learning, accessed January, 20, 2014
} 
Department of Education (2010, p. 12), personalization is considered as encompassing individualization and differentiation:

Individualization refers to instruction that is paced to the learning needs of different learners. Learning goals are the same for all students, but students can progress through the material at different speeds according to their learning needs. For example, students might take longer to progress through a given topic, skip topics that cover information they already know, or repeat topics they need more help on. Differentiation refers to instruction that is tailored to the learning preferences of different learners. Learning goals are the same for all students, but the method or approach of instruction varies according to the preferences of each student or what research has found works best for students like them. Personalization refers to instruction that is paced to learning needs, tailored to learning preferences, and tailored to the specific interests of different learners. In an environment that is fully personalized, the learning objectives and content as well as the method and pace may all vary (so personalization encompasses differentiation and individualization).

To describe (open) education, we use the five components open education model (5COE model) of Mulder and Janssen (2013). In this model, three components comprise education on the supply side: learning materials, learning services, and teaching efforts. Two components are on the demand side: the demand from the learner and the demand from the environment (society).

The process of mass customization in educational terms is based on a demand from a (group of) learner(s) where the combination of learning materials, learning services, and teaching efforts should fulfill certain explicit or implicit requirements and a supply of building blocks (learning materials, services, and teaching efforts) that can be combined into an offer fulfilling the demand. The resulting offer should comply with several general requirements (e.g., complying with demands at curriculum level) and potentially there is a significant number of building blocks available. To this end, the institution can meet part of the demand from a learner. Elements like determining the learning goals, adaptation of the learning process based on feedback from the learner, or assessing the level of prior knowledge are not part of this approach. We consider mass customization as an approach fitting in a continuum in approaches to tailor education to the demand of an individual learner, as depicted in Figure 1. 


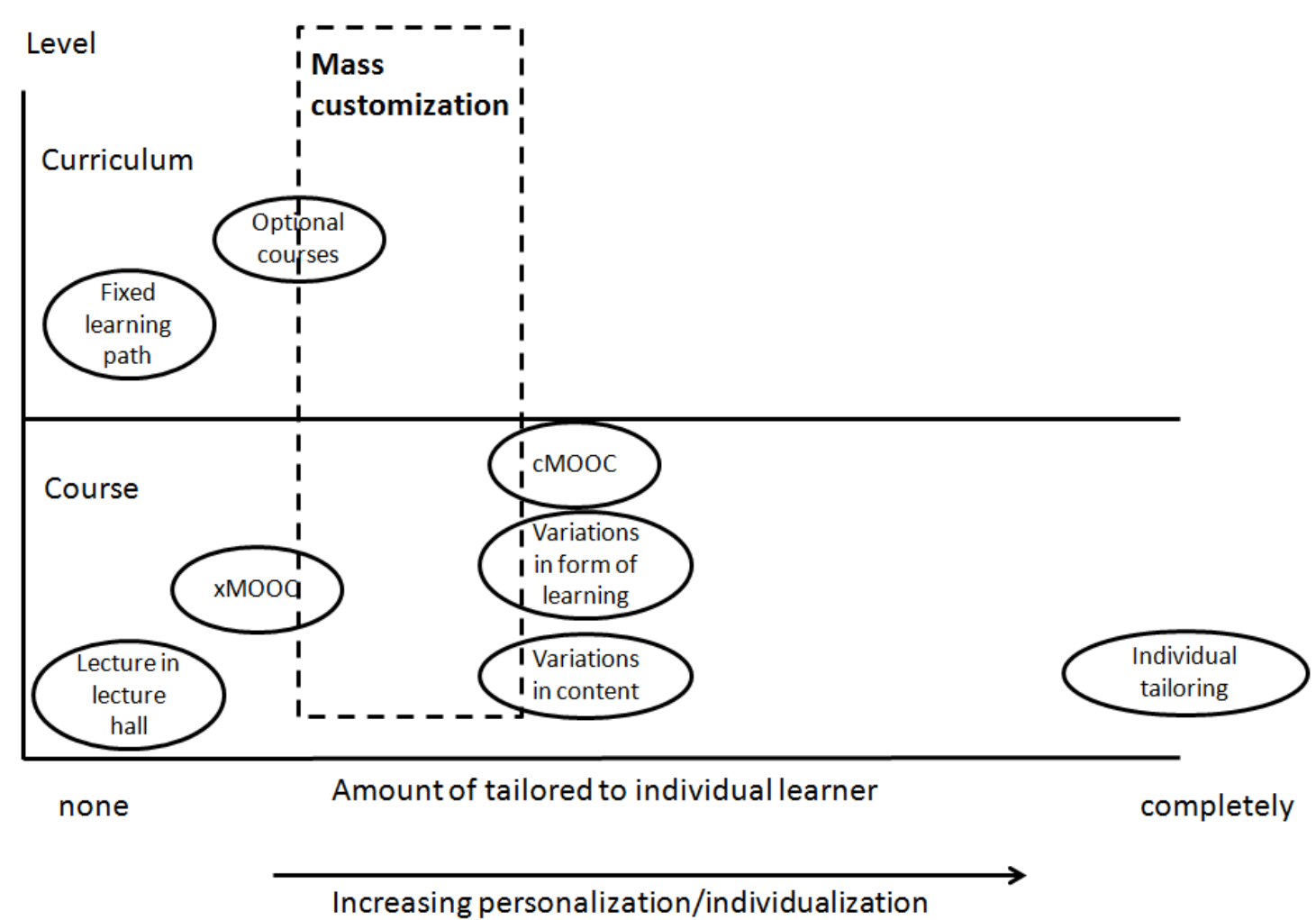

Figure 1. Continuum of tailoring education.

In Figure 1 we distinguish two levels of tailoring: course or curriculum (the vertical axis). Some examples of approaches to realize a certain amount of tailoring are added in the framework.

In this paper we will elaborate on this. We start with attempts in the educational field dating back to the 90's of the last century. Then we will introduce some terminology to use and solutions the industry has developed in both structuring products and ITsupport for the end user. We will apply these insights to the field of education. We conclude with a view on future work in this field.

\section{Current Work}

The dawn of a more demand driven approach in education is described in Kirschner and Valcke (1994). They describe that the need for a demand driven approach started at the beginning of the 20th century. They foresee development to a more demand driven approach using IT going through three stages:

- IT as a substitute for something a teacher or a student uses. An example from the past is the change from hand-written slides to PowerPoint. 
- IT as a means for innovation. An example is using a virtual lab by students for doing experiments that are either too complicated or too expensive to offer from a single institution. Examples of these can be found at http://www.vlab.co.in/index.php.

- IT as a means for transformation. Current concepts, paradigms, theories and laws of education are no longer valid and are replaced by others. We are far from this situation yet, but the concept of flipping the classroom (Barrett, 2012) is an example where IT transforms educational concepts.

In current society, where prosperity depends on a well-developed knowledge economy, the growing demand for both well-educated youngsters and a lifelong learning working staff is even more urgent. On the other hand, costs for education are under pressure both because of this growing demand and because of the current economic crisis. The cry for an efficient and effective learning process is heard (e.g., in Universities UK, 2011). To fulfill these needs, education has to become more geared to the demands of the individual learners to be as effective as possible. However, tailoring educational supply to each single demand is far from efficient. A balance between these two conflicting demands can be found in an approach where learning is tailored to the demands of the individual learner, using IT as means to realize this.

One of the early attempts to realize this situation came with the Mercator system (Valcke et al., 1997; Martens et al., 1997). This system was based on an approach where course materials were generated based on student characteristics. These characteristics could for example be determined by means of pretests. The database of materials for this system contained both domain specific content (55\%) and didactical components (45\%). The granularity of the content varied between chapters, themes, and subthemes. Students select topics from a table of contents. This table of contents can be tailor made, dependent on student characteristics. Learning materials for the selected topic and appropriate didactical elements are determined by the system.

The approach by the Mercator system turned out to be too complex to handle. Offering several different pedagogical models as a starting point resulted in offering several differing contents and learning activities. This needed a granularity of materials in the database that was too detailed to be workable ${ }^{2}$. Different versions of the same learning materials sometimes needed adjustments on the level of a paragraph. This led to a combinatorial explosion of versions of basically the same learning material that could hardly be managed. Another drawback is the level of detail with which each instance of learning material has to be described in order to make it available and usable for a specific learning demand.

${ }^{2}$ According to personal communication with Prof. dr. Rob Martens, one of the participants in the Mercator project. 
Experiences with Mercator led to the development of EML (Educational Modeling Language) (Koper \& Manderveld, 2004). EML is a semantic notation for units of learning to be used in e-learning. It enables specification of learning technology taking into account a pedagogical framework of different types of learning objects, expressing the relationships between the typed learning objects and defining the structure for the content and behavior of the different learning objects. The current standard IMS Learning Design (http://www.imsglobal.org/learningdesign/) is based on the first specifications of EML.

Several approaches use a hierarchical task network (HTN) planner to generate course materials, adapted to the competencies of the learner. Ulrich and Melis (2009) implement an HTN planner in an expert system. This approach also needs a large amount of learning materials available to be able to generate adapted courses. In Morales et al. (2009), IMS-LD is used as a basis to generate conditional learning pathways, able to adapt to run time events. This approach too requires a large amount of learning material, described in an IMS-LD vocabulary.

IMS-LD also forms the basis for an approach sketched in Hernández et al. (2009). Here a model of the user is built to be able to take into account intrinsic characteristics of the user (e.g., learning style) and the desired and achieved competencies in the learning process.

Karampiperis and Sampson (2006) describe an approach where personalization of the learning materials is limited to adaptive hypermedia systems.

Another perspective on mass customization of education is given in Asseldonk and Mulder (2004). They describe the following characteristics of mass customization.

- Batch versus flow. A batch is characterized by a programmed system, fixed rules, and users bound by these rules. Characteristics of a flow are a selfregulating system, situational rules, and autonomous users. A batch describes a closed educational system, whereas a flow describes a more open educational system.

- Atomization and navigation. Atomization is comparable with the building blocks as described before. For the user, this leads to a demand of support for navigating through the space of learning materials. The authors believe the latter to be one of the main tasks for institutions for higher education.

The growing availability of OER and other means of open education (e.g., MOOCs) provides new opportunities for creating tailor made learning pathways, eventually leading to credits or a degree. Horn and Christensen (2013) foresee a future where learning becomes a continuous, on-the-job process. The need for customization will then drive toward just-in-time mini-courses, made available in open offerings. We believe that in this situation a closed system still will have its value, with a curator's role 
in determining the quality of available learning materials and structuring the space of learning materials (e.g., by defining curricula or smaller learning pathways).

In Shoham (2012), a similar vision on future education is described, envisioning content units smaller than current courses and remixing this content to new content, customized for a learner. Neither Horn nor Shoham describes how to realize the situation.

Approaches for mass customization in engineering education are sketched in Rippel et al. (2012) and Mistree et al. (2012). These descriptions do not take into account the reuse of OER, are limited to only very specific situations, or provide no choice for the learner to create his/ her own learning path.

All approaches sketched do not provide means to realize the desirable situation where a customized demand can be met using a mixture of OER and closed materials with acceptable quality against acceptable costs. This justifies our search for an approach inspired by successful attempts in another field.

In the next section we will describe mechanisms that industry has developed to overcome the problems in mass customization for products as described. These mechanisms are the basis of IT support for a customer to match a personal demand to an individualized version of a product.

\section{Mass Customization in Industry}

Industry made the move to mass customization several decades ago. The rise of computing power and the growing abilities offered by the Internet provided the means to implement concepts of research into this subject. Products are designed as product families. Ulrich and Tung (1991) define a product family as "a large set of end products constructed from a much smaller set of components." These kinds of products are highly modularized, and use standardized interfaces to fit the modules together to a customer specific end product. Production of the end product can be characterized as assembleto-order: The end product is built to customer specifications from a stock of existing components. Assembling an end product takes into account already existing modules and the interfaces to use them.

This move enabled producers to combine the advantages of mass production, high quality and relatively cheap products, with customer specificity. This customer specificity has to be seen as bounded within the option set envisaged when engineering the product family.

One of the advanced examples is the car industry. Potential buyers for a car can use user friendly configurators that lead them through the process of assembling a car by selecting the components and features that most closely adhere to their demand. These 
configurators are indispensable because of the combinatorial explosion of different end products that arise when the different versions of the components and their features are combined.

Examples of such configurators are http://www.volkswagen.co.uk/\#/new/ passatvii/configure/ (Volkswagen Passat) and http://www.volvocars.com/uk/salesservices/sales/pages/car-configurator.aspx (Volvo).

The cornerstone of these configurators is a model of the product for which mass customization is needed. We will start by introducing the terminology to describe these models.

Some "things" in the real world are worthwhile to describe. Such a "thing" is called an object. A description of an object serves a goal and is mostly used as a means of communicating about the object. A group of similar objects is called an object type. The properties of an object type that are part of the description are called attributes or parameters. The difference is that a parameter can have several values, in most cases determined by the customer. When each attribute and parameter gets a value, we get an instance of an object type.

Which parameters a description of an object type contains is determined by the purpose of the description. Essential parameters are those attributes where different values describe essentially different instances of the object type for the purpose it is described. A specialty originates when the range of values for the essential parameters is constrained. From a specialty a variant (or configuration) is created when all parameters get a value. Constraining the range of values for parameters is called parameterizing.

\section{Example: car}

Suppose we want to describe a car for use in a configurator. Based on experience of the manufacturer, the most important parameter for this purpose is whether the car has a diesel or petrol engine. Table 1 lists the different terms we have introduced for this situation. 
Table 1

Illustration of ATO Terminology

\begin{tabular}{|c|c|}
\hline Term & Example \\
\hline Object & Car in the real world \\
\hline Object type & Cars of the same type and model \\
\hline Parameter & 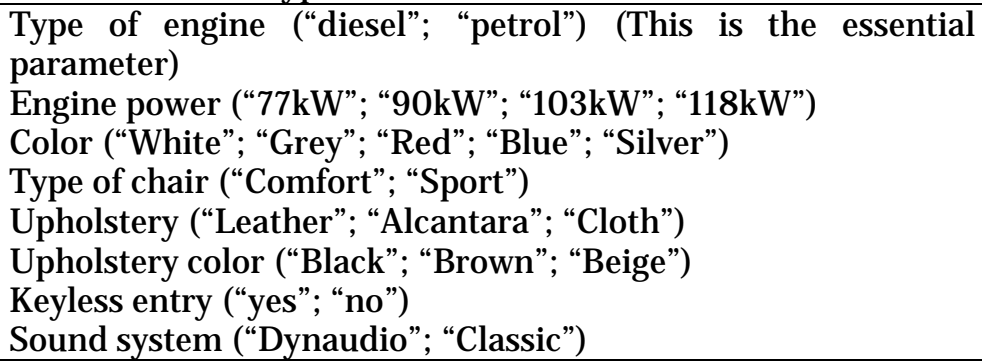 \\
\hline Specialty & $\begin{array}{l}\text { Diesel car (Type of engine="diesel") } \\
\text { Petrol car (Type of engine="petrol") }\end{array}$ \\
\hline $\begin{array}{l}\text { Variant } \\
\text { (configuration) }\end{array}$ & $\begin{array}{l}\text { Example of a variant of a diesel car: } \\
\text { Engine power: } 77 \mathrm{~kW} \\
\text { Color: Silver } \\
\text { Type of chair: Comfort } \\
\text { Upholstery: Cloth } \\
\text { Upholstery color: Black } \\
\text { Keyless entry: yes } \\
\text { Sound system: Dynaudio }\end{array}$ \\
\hline
\end{tabular}

In most cases, creating a variant by selecting values for each non-essential parameter is subject to constraints. Two special types of constraints can be distinguished:

- Inclusions: The value of parameter $\mathrm{A}$ is determined by the value of parameter $\mathrm{B}$

- Exclusions: Certain values of parameter A are not allowed when parameter B is given a certain value

For the car, an example of an inclusion could be "When the upholstery is cloth, the upholstery color is black". An example of an exclusion could be "When the type of chair is sport, the upholstery cannot be alcantara". A variant that meets all constraints is called a valid configuration.

In practice, the number of parameters to select and determine is much higher. Even more complex in reality is taking into account special offers, bundled packages (offering a discount when selected as a whole), and the numerous constraints affecting options of parameters. Even in this simplified example of a car configuration, not taking into account constraints, the total number of valid configurations is 2,880. Managing this information becomes even more difficult when new types of cars are introduced, leading to extra values for parameters or even to new parameters. For example, the parameter "keyless entry" did not exist until recently. 
A big advantage of this modeling approach is the easy maintenance when new features become available. To add new features to the model, a new parameter or new values for existing parameters are added, together with possible constraints on this.

An important prerequisite that enables products to be customized is a modular structure of the physical product with well-defined interfaces. Especially when (for reasons of efficiency) modules should be usable for different specialties or even for different types of products, this calls for a high degree of standardization of the interfaces to keep it manageable. An example are the screws used to connect two modules to each other. DIN (Deutsches Institut für Normung) maintains an extensive list of standards for these screws (DIN, 2013). A big advantage of these standards are the possibilities to outsource production of those screws to third parties where referring to the standard suffices. However, standards only have limited power. Simple things such as screws can be standardized. But if components become slightly more complex, such standardization becomes rapidly more difficult. For example, the positioning of the screw holes, which allow two components to be bolted together is not standardized. The car manufacturer will usually determine this. Only some exceptions of standardization at a higher level are known. One is the placement size for a car radio. Even something as easy to envisage as a standard for the placement of attachment positions of wheels is car and model specific. The main interfaces between components are therefore brand specific.

The configurator contains the knowledge of parameters, its values, and its constraints and guides the customer through the process to end up with a valid configuration of the car. Customization, however, is only limited to the parameters shown. So a demand for a car with an electrical engine cannot be customized in the example earlier shown. The customer will have the options to either accept this or go to another manufacturer who will give him this opportunity.

The parameters with which object types are described determine the modules made visible for a customer. The elements used for constructing the module remain invisible for the customer. A balance should be available between the number of parameters made visible to the customer and the complexity of managing this amount of information (including the constraints between the parameters). Choosing the right parameters will be market driven. For cars, types of engine and color are important parameters for a customer to determine. Rigidity of the bodywork however is for most customers not important, so this property of a car is not offered to a customer.

Summarizing, the most important lessons from industry for mass customization are:

- The basis is a model of a product where the building blocks are modeled using parameters and constraints between those parameters. 
- Strive for the right granularity of elements that builds up an end product. A balance should be found between a manageable complexity of combinations of elements and the demands the market has on customization to its needs.

- Interfaces between modules are well-defined. Where possible, interfaces are standardized, using internationally accepted standards. However, as soon as complexity and specificity of the interface increases, this will no longer be possible. In that case a more local scope (e.g., a car manufacturer) will need to be present where these interfaces are defined.

- ATO does not support full customization. For those situations, an engineer to order or small size production situation is suited. This costs (a lot) more for the customer. To formulate it another way, a customer can customize a Volkswagen Passat largely to his demands. When a special demand cannot be met however, there are two options left: Accept this (and pay a moderate amount of money) or look for another solution (that almost surely will cost a lot more; see for example the very high prices of the customer specific adaptations offered by Brabus (http:// www.brabus.de).

- To guarantee a valid configuration, configurators to guide the customer through the attributes and choices that have to be made are indispensable because of the complexity of the product model.

\section{Mass Customization in Education}

In this section we will elaborate on applying the theories and practices of mass customization from industry to education. The objectives for doing so are identical to those achieved in industry: to combine high quality and relatively low costs with customization (within limits). Our starting point is the product model for the educational field as depicted in Figure 2. 


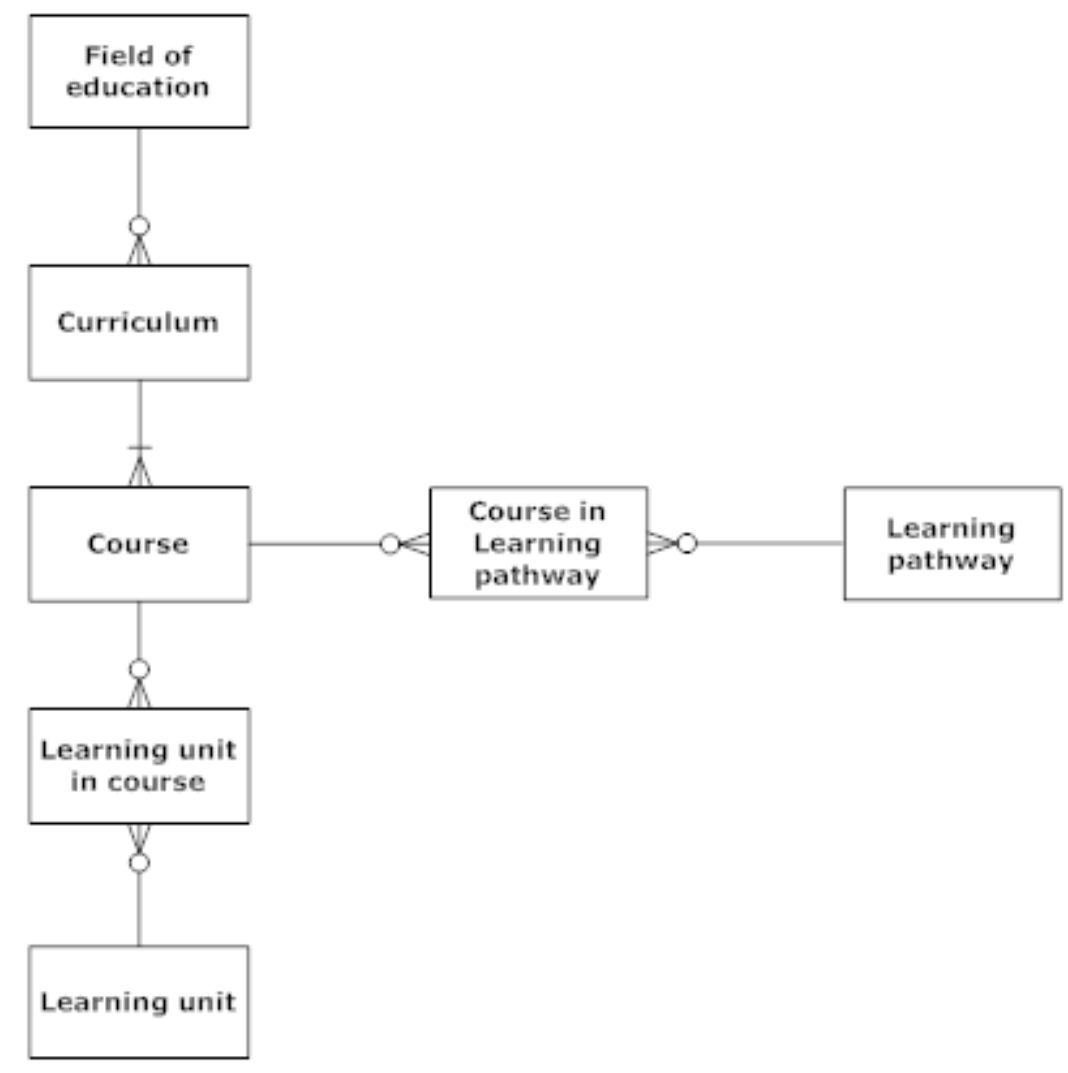

Figure 2. Product model for education.

A description of this model: For a field of education (e.g., computer science), there exist many curriculums. Each curriculum is built up of courses (e.g., a course on structured programming), each course is built up of learning units (e.g. a unit on control structures in a programming language). Courses can be organized in learning pathways. A learning pathway is the way an individual student or group of students chooses to go through a (part of a) curriculum.

In this model, variations are possible on several entities:

- course, where variations can exist in learning units (e.g., the possibility to select optional learning units or the form of a learning unit [digital or non-digital])

- curriculum, where variations can exist in the composition in courses (e.g., the possibility to select one or two courses from a list of many)

- learning pathway, where variations can exist in the way the courses are taken by a student (e.g., the order of the courses or the choice between an online or an offline variant of a specific course) 
In this vision, the learning unit is the building block where all variants are built upon. A course is an instantiation of variants of learning units, and a learning pathway is an instantiation of variants of courses in a specific sequence. Customization offered to the student can be on

- learning pathways, in variations of courses (a student can assemble an individual pathway through courses);

- courses, in variations of learning units (a student can assemble his or her own course or parts of courses out of learning units, combined with variations in learning services and teaching efforts).

A curriculum determines certain constraints on possible variations. For example, in ACM (2001) 14 knowledge areas are mentioned for a computer science curriculum. Also, high-level learning objectives are named, the knowledge and skills for a bachelor or master in computer science, and for each subject the minimum number of hours to be spent in the curriculum. A valid configuration of courses should comply to this description of a curriculum.

The starting point for a student will be configuration of his/her preferred learning pathway. To illustrate how parameterization of learning units, courses, and learning pathways could look in an educational environment, we will use the following fictitious example.

\section{Example: A Very Short Curriculum for Computer Science}

Consider courses in a curriculum for Computer Science as depicted in Table 2.

Table 2

Curriculum Computer Science

\begin{tabular}{|l|l|}
\hline Course & Remarks \\
\hline Introduction in CS & Mandatory \\
\hline Introduction in programming & Mandatory \\
\hline Advanced programming & Optional \\
\hline Databases 1 & Mandatory \\
\hline Databases 2 & Optional \\
\hline Data modeling & Optional \\
\hline Communication networks & Mandatory \\
\hline Calculus for CS & Mandatory \\
\hline Internship & Mandatory \\
\hline Constraints \\
\hline Exactly 1 optional course must be selected \\
\hline
\end{tabular}


Each course consists of several learning units. Experiences with this curriculum shows that the most important parameter for a course is the mode of delivery. To illustrate parameterization of a course, Table 3 provides one for the course Introduction in CS. This course is made up of four learning units. For the third and fourth unit, a student can select from 4 resp. 3 different options. Each learning unit is delivered in several formats. There are several modes of delivery for the course and the student can also select between several options for the final assessment and tutoring during the course. Note that the latter elements are examples of learning services and teaching efforts. There are several constraints for the parameters. There are constraints on modes of delivery in relation to start date of the course, start date and form of final assessment, and on combinations of options for learning unit 3 and 4.

Table 3

Example of Parameterization of a Course

\begin{tabular}{|c|c|}
\hline Term & Example \\
\hline Object & Course Introduction in CS \\
\hline Object type & $\begin{array}{l}\text { Course Introduction in CS for an individual student or a group of } \\
\text { similar students }\end{array}$ \\
\hline Parameter & 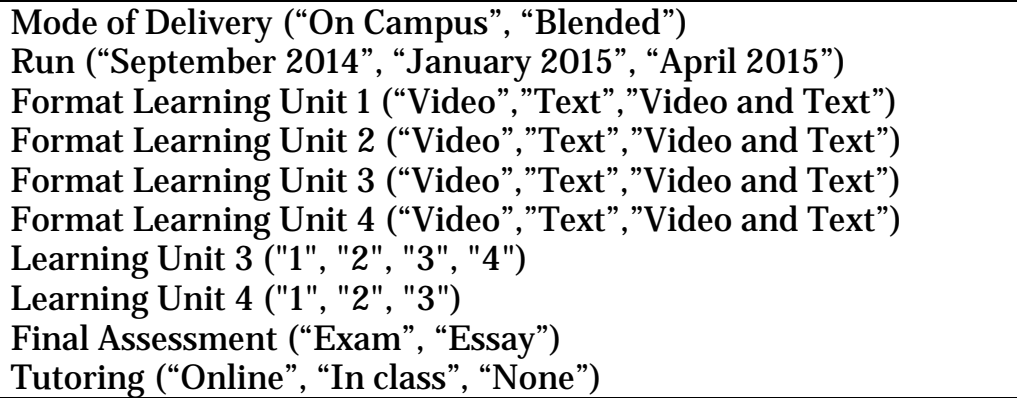 \\
\hline Specialties & $\begin{array}{l}\text { Blended course Introduction in CS (Mode of } \\
\text { delivery="Blended") } \\
\text { On Campus course Introduction in CS (Mode of delivery="On } \\
\text { Campus") }\end{array}$ \\
\hline $\begin{array}{l}\text { Variant } \\
\text { (configuration) }\end{array}$ & $\begin{array}{l}\text { Example of a variant of a blended course: } \\
\text { Run: September } 2014 \\
\text { Format Learning Unit } 1 \text { ("Video") } \\
\text { Format Learning Unit } 2 \text { ("Video and Text") } \\
\text { Format Learning Unit } 3 \text { ("Text") } \\
\text { Format Learning Unit } 4 \text { ("Video") } \\
\text { Learning Unit } 3 \text { ("2") } \\
\text { Learning Unit } 4 \text { ("1") } \\
\text { Final Assessment ("Essay") } \\
\text { Tutoring ("In class") }\end{array}$ \\
\hline Constraints & $\begin{array}{l}\text { If Mode of Delivery="On Campus" Then Startdate="September" } \\
\text { If Mode of Delivery="'On Campus" Then Tutoring<>"Online" } \\
\text { If Startdate } \diamond \text { "September" Then Final Assessment = "Essay" } \\
\text { If Learning Unit } 3=\text { =1" Then Learning Unit } 4<\text { "2" }\end{array}$ \\
\hline
\end{tabular}


Table 4 depicts a parameterization for a learning pathway. It is assumed that no more than two courses are allowed to be taken simultaneously. Furthermore, each learning path should start with Introduction with CS and end with the internship. The most important parameter for a learning pathway is which optional course is selected.

Table 4

Example of Parameterization of a Learning Pathway

\begin{tabular}{|c|c|}
\hline Term & Example \\
\hline Object & Learning pathway \\
\hline Object type & $\begin{array}{l}\text { Learning pathway for an individual student or a group of similar } \\
\text { students }\end{array}$ \\
\hline Parameter & 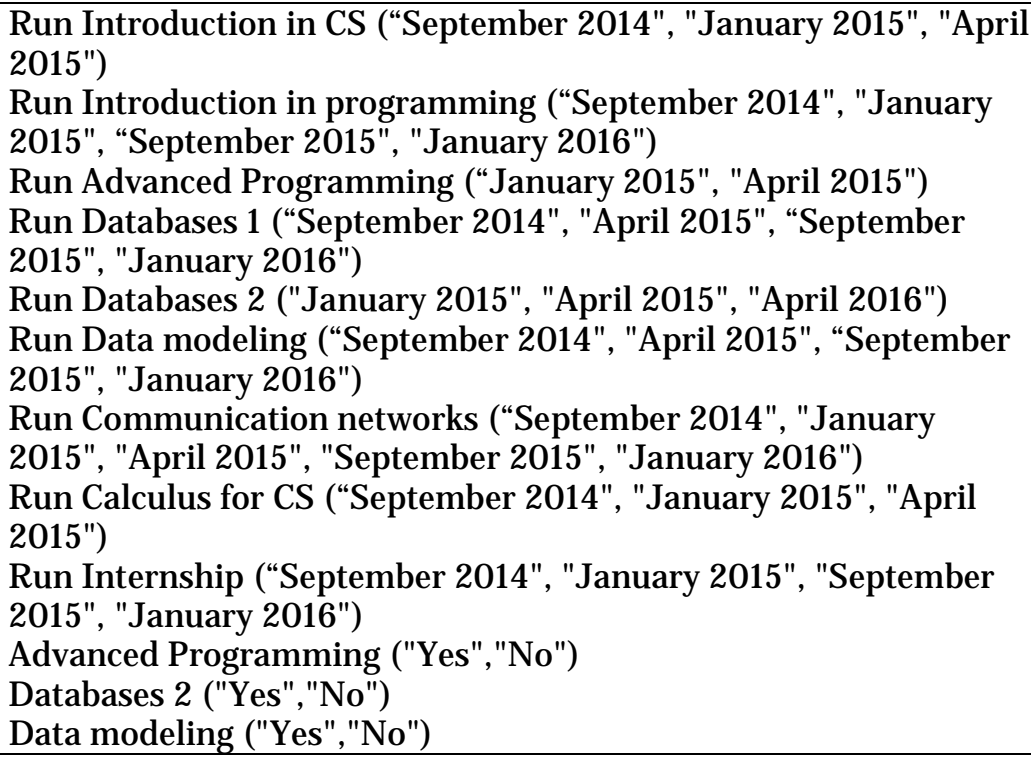 \\
\hline Specialties & $\begin{array}{l}\text { Learning pathway Programming (Advanced Programming="Yes") } \\
\text { Learning pathway Databases (Databases } 2=\text { "Yes") } \\
\text { Learning pathway Modeling (Data modeling="Yes") }\end{array}$ \\
\hline $\begin{array}{l}\text { Variant } \\
\text { (configuration) }\end{array}$ & $\begin{array}{l}\text { Example of a variant of a Learning pathway Programming: } \\
\text { Run Introduction in CS ("September 2014") } \\
\text { Run Introduction in programming ("September 2014") } \\
\text { Run Advanced Programming ("April 2015") } \\
\text { Run Databases } 1 \text { ("April 2015") } \\
\text { Run Communication networks ("J anuary 2015") } \\
\text { Run Calculus for CS ("J anuary 2015") } \\
\text { Run Internship ("September 2015") }\end{array}$ \\
\hline Constraints & $\begin{array}{l}\text { Introduction in CS in first period } \\
\text { Internship as last course } \\
\text { No more than } 2 \text { courses with same run date } \\
\text { Exactly one of the values for Advanced Programming, Databases } 2 \\
\text { or Data modeling equals "Yes" }\end{array}$ \\
\hline
\end{tabular}

Although this example describes a very simple situation, the number of possible configurations (not taking into account the constraints) is already large. Assuming the 
same parameterization for each course as the one that is described for the course Introduction in CS, the total number of learning pathways is 3 specialties * 9 courses * 4 periods (average)* 2 course specialties $* 4$ learning units $* 3$ formats $* 4$ options for learning unit $3 * 3$ options for learning unit $4 * 2$ final assessments $* 3$ tutoring modes $=$ 186,624 . The number of valid configurations is smaller, but still significant.

In reality, the number of parameters will be much larger, both for a course as for a learning pathway. Furthermore, the number of courses that make up a curriculum is much larger than the number from our example. Besides, the following requirements count for a curriculum as a whole:

1. clear, preferably unambiguous use of language;

2. no overlap (subjects handled in several places in the curriculum, whether or not consistently treated);

3. no missing parts of relevant subjects;

4. the right level (of abstraction) on the right place in the curriculum.

These requirements for a curriculum as a whole should be translated into parameters and constraints in the product model.

IMS Learning Design (IMS LD) provides us with a description of which elements together build up a course (Koper \& Manderveld, 2004). This specification dates back to 2003. The basic unit within IMS LD is the 'unit of learning'. This unit is described by the attributes depicted in Figure 3 (Koper \& Manderveld, 2004). 


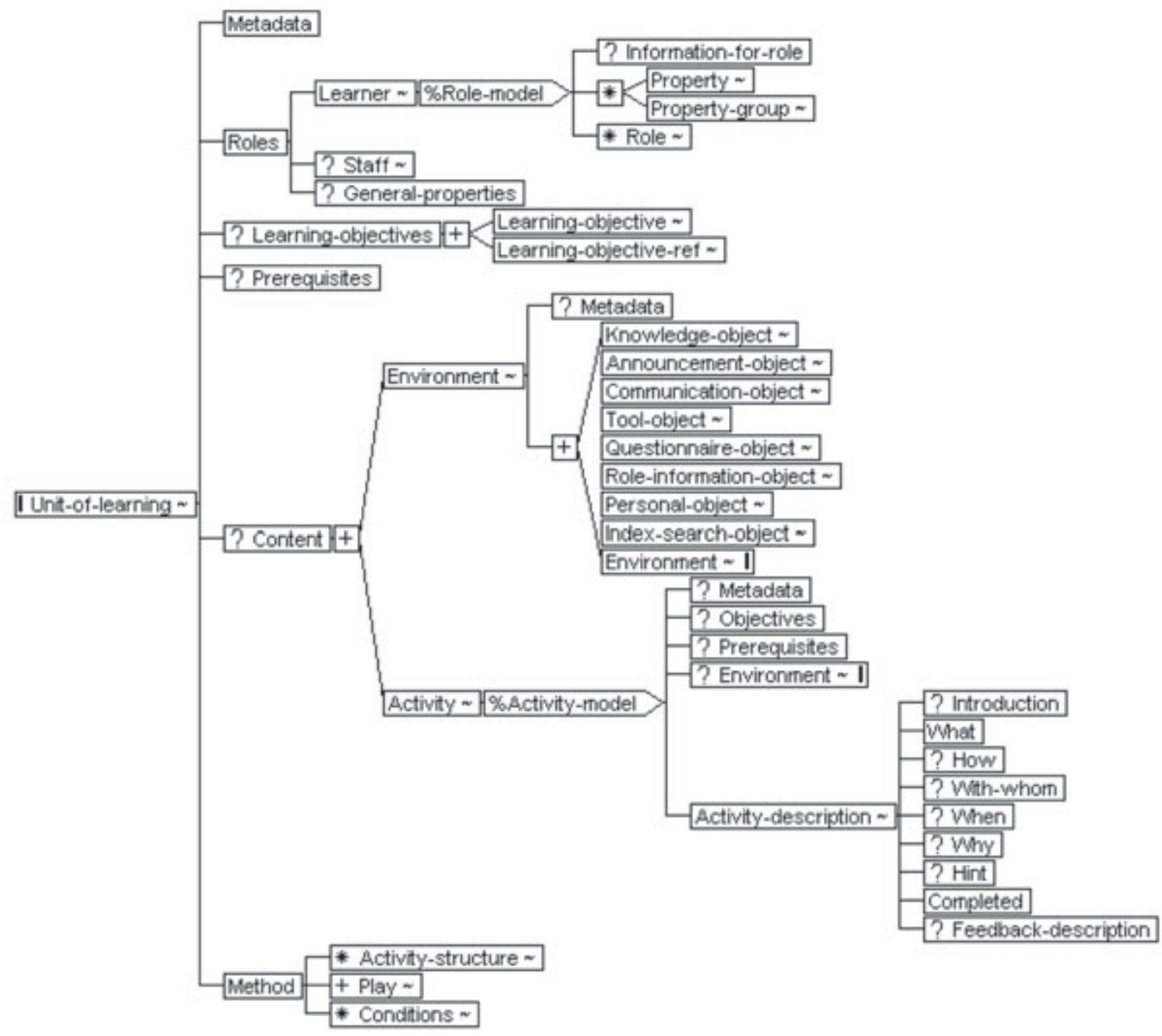

Figure 3. Basic structure of IMS LD.

The attributes given in this model can be used as parameters to create variants of learning units. In our example, we used the roles attribute as parameter for variants in tutoring. The attributes can also be used to provide the student with more information on a learning unit, so his selection will be more informed. But variants also arise due to flexibility in services as offered by the institution (e.g., the option for a blended or an online variant for a course in our example).

An important difference between the modeling of products in the industry and for education is the lack of standardized interfaces between modules in the latter situation. This complicates configuring a curriculum when (whether or not open) available sources from elsewhere should be combined into a coherent whole. In this situation, standardization can be initiated by standardizing learning objectives (for a course or course section). The description of learning materials can then be expanded by enumerating to which learning objectives the materials contribute. An attempt at such 
standardization is the Achievement Standards Network (ASN, 2013). A reasonable alternative is to standardize at the level of institution. Learning materials from outside the institution can then be added to its own structure by a careful process of selection and (limited) adjustment. The lack of standards on interfaces and the specific demands on curriculum and quality of OER leads us to the conclusion that an ATO approach is currently only viable in education when the institution orchestrates the process.

Another difference is that in industry the end product is almost completely determined by physical components. In the educational field, this is a mixture of physical components (the learning materials), learning services, and teaching efforts.

As in industry, IT support is indispensable to both the modeling of the product and assembling a valid configuration. The product data are modeled as a bill of material, in which the constraints are also defined. An important requirement of a bill of material is to manage the potential explosion in combinations of modules. A generic bill of materials (Hegge \& Wortmann, 1991) is a type of bill of materials developed specifically for these kinds of products. Also, a configurator, built upon the product model, is the tool to be used by the learner to assemble a learning pathway on demand. The challenge for the institution offering these possibilities is to organize the supply in such a way that groups of more or less homogeneous types of learners can be accommodated, where the individual user gets the feeling that his/ her unique situation is taken as a starting point.

\section{Validation}

To validate the idea as described and determine its perceived added value, eight experts where interviewed. Their expertise was in educational technology and OER. Some experts were responsible for offering a curriculum. In each interview, the idea was explained to the expert. Then $\mathrm{s} /$ he was asked to judge the added value of this approach (ranging from 1 = no added value; 2 = limited added value; 3 = reasonable added value; 4 = significant added value; $5=$ high added value) and to explain their opinion. This led to the following findings.

Seven out of eight of the experts judged the added value with 3 or higher (2 scored 3; 4 scored 4; and 1scored 5). Arguments provided were:

- This approach creates a clear view for the learner on the supply of an institution and the level of tailoring to the demands of him/ her. A learner gets more insight into expectations and individual concessions when confronted with the modeled curriculum.

- The approach can also provide insight to the institution in how tailored their supply can be. 
- Situations that occur in practice can be modeled using this approach, for example a software curriculum at the University of Utrecht with $50 \%$ free choice of courses, having to satisfy several constraints on pre-knowledge available, per period limited number of courses to select, and so on. This situation could profit from this modeling approach.

- An eye opener is the parameterization of services and not only materials.

- When different institutions use this approach, a future learner can find out which institution will have the most/ best tailored offer for him/ her.

- When supported by configurators, process data can be analyzed to find out which learning paths and/ or which course configurations will lead to the best results (learning analytics). But this should be handled carefully to not base decisions only on averages. Using a configurator will also ease adding recommender functions for certain parameters.

- This approach is especially worthwhile in a life long learning setting when the parameters make possible that the resulting configuration is closely related to the field where the learner is working, making transfer of the subject matter to practice easier (e.g., by variations in cases).

Concerns about this approach were also mentioned. A single expert (who was responsible for a curriculum) judged the added value as 2, because a necessary precondition is to make the organization adapt to this situation. This concern was mentioned by other experts. To realize a setting where this approach is possible, the learning goals and content should be described carefully and some level of standardization in building courses and curriculum should be present. Furthermore, comparing activities of a teacher with those of a car manufacturer will possibly lead to resistance of acceptance of the idea. Another consideration, mentioned by several experts, was that in many cases a mixture of this approach and individual tailoring will be necessary. Parameterization will model $80 \%$ of the demand. The remaining $20 \%$ will be created tailor-made against higher costs. Two experts questioned the business case behind this approach. When an institution embraces some form of mass customization, the costs per student will probably rise. What drivers will force an institution to start with this approach?

Several experts also made remarks on extensions of use for this approach, not limited to a regular curriculum and the possible role IMS- $L D$ could play:

- The approach is also useful for post initial education. The demand in that case is not determined by a curriculum with learning goals and demands on level and variety to have a valuable certificate or degree. But in many cases section specific demands exist for learning goals. So there exist a common set of agreements from which the parameters to vary can be derived. 
- IMS-LD provides modeling of education on a deeper, more individualized level, but it can feed modeling on the level as presented here.

This leads us to the conclusion that the idea as sketched is worthwhile to pursue further. In the next section we will sketch some possible actions.

\section{Conclusions and Future Research}

When we look at the requirements and challenges mentioned in the introduction, it can be noticed that an approach for mass customization based on ATO, if successfully transferred to the field of education, would deal with a number of the issues mentioned.

- The ability to provide variety enables adapting the educational product to requirements stemming from differences between types of students, context, and locality.

- The ability to provide acceptable development costs using this mass customization approach could give an answer to current problems with unclear business models and high costs of adaptation.

- The ability to provide acceptable quality is a serious hindrance to current acceptance of OER. The ability to handle this issue would strongly support adoption of OER.

By selecting a learning unit as granularity for the modeling of the product, available OER can be readily reused in the offerings. What is needed though to increase the findability are more detailed descriptions along with the OER on learning goals, pedagogy, required foreknowledge, and so on.

As was also mentioned in the Introduction, the demand for offering personalized learning is expected to grow in the next decade (Horn \& Christensen, 2013). In that situation, there will be a need for a supply of learning materials (both closed and open) where this supply as well as possible (but not necessarily 100\%!) fits the individual demand of a learner. When this expectation comes true, the university that succeeds in offering the best 'fit' for the potentially largest target group will gain a competitive advantage.

Creating the best 'fit' takes into account both learning technology aspects (e.g., variance in pedagogical approaches) and organizational variations (e.g., offering both f2f as online courses, paced, and not paced). Opportunities to realize such offerings can be enhanced by using techniques like learning analytics and developments like the semantic web. These techniques can be used to add to context related properties of the learning materials, thereby realizing a better findability for the OER and providing an end result better suited to the individual user with relatively low costs. 


\section{Acknowledgement}

We would like to acknowledge the following persons for their willingness to provide the validation feedback: Prof.dr. Lex Bijlsma, Dr. Pierre Gorissen, Dr. Monique J ansenVullers, Dr. Karel Kreijns, J ocelyn Manderveld MSc, Eric Slaats MSc, Fred de Vries MSc and Nicolai van der Woert MSc. 


\section{References}

ACM (2001). Computing curricula 2001 computer science. Association for Computing Machinery. Retrieved from

http:// www.acm.org/ education/ education/ education/curric_vols/ cc2001.pdf

ASN (2013). Achievement standards network. Retrieved from http:// asn.jesandco.org/

Asseldonk, T., \& Mulder, F. (2004). Massa-individualisering van hoger onderwijs (Mass individualization of higher education) (in Dutch). Redes opening van het academisch jaar. Open Universiteit: Heerlen, 19-30. Retrieved from http:// www.ou.nl/documents/ 10815/4100960e-6314-4471-8fb08dfd88d8d7dd

Barrett, D. (2012). How "flipping" the classroom can improve the traditional lecture. The Chronicle of Higher Education. Retrieved from http:// chronicle.com/article/How-Flipping-the-Classroom/130857/

Bates, A. W. (2005). Technology, e-learning and distance education (2 $2^{\text {nd }}$ ed.). New York, NY: Routledge.

Commonwealth of Learning (2011). Guidelines for open educational resources (OER) in higher education. UNESCO. Retrieved from http:// unesdoc.unesco.org/images/ 0021/ 002136/213605e.pdf

DIN. (2013). List of DIN standards. Retrieved from http://en.wikipedia.org/wiki/List_of_DIN_standards

Hegge, H. M. H., \&Wortmann, J . C. (1991). Generic bill-of-material: A new product model. International J ournal of Production Economics, 23(1-3), 117-128.

Hodgkinson-Williams, C. (2010). Benefits and challenges of OER for higher education institutions. The Commonwealth of Learning. Retrieved from http:// www.cet.uct.ac.za/ files/file/2010/HodgkinsonWilliams\%202010\%20Final-1.pdf

Horn, M., \& Christensen, C. (2013). Beyond the buzz, where are MOOCs really going? Retrieved from http:// www.wired.com/opinion/2013/02/ beyond-the-moocbuzz-where-are-they-going-really

Kirschner, P., \&Valcke, M. (1994). From supply driven to demand driven education: New conceptions and the role of information technology therein. Computers in Human Services, 10(4), 31-53. 
Koper, R., \&Manderveld, J . (2004). Educational modelling language: Modelling reusable, interoperable, rich and personalised units of learning. British J ournal of Educational technology, 35(5), 537-551.

Martens, R., Weges, H., \& Valcke, M. (1997). Elektronischeleermaterialen. Drie case studies (Digital learning materials. Three case studies) (in Dutch). Landelijke dag studievaardigheden, Heerlen. Retrieved from http:// www.open.ou.nl/lds97/ elektronische leermat.htm

Matkin, G. W. (2009). Institutional sharing of OpenCourseWare across national boundaries: A case study and historical first in higher education. Distance Education Report, 13(10), 3, 7-8.

Mistree, F., Panchal, J. H., \& Dirk Schaefer (2012). Mass-customization: From personalized products to personalized engineering education. In A. Groznik (Ed.), Pathways to supply chain excellence. InTech. Retrieved from http:// www.intechopen.com/ books/ pathways-to-supplychain-excellence/ masscustomization-from-personalized-products-to-personalized-engineeringeducation

Morales, L., Castillo, L., \& Fernández-Olivares, J . (2009). Planning for conditional learning routes. In MICAI 2009: Advances in Artificial Intelligence, 384- 396

Mulder, F., \& J anssen, B. (2013). Opening up education. In RJ acobi, H. J elgerhuis \& N. van der Woert (Eds), Trend report open educational resources 2013 (pp. 36-42). SURF SIG OER, Utrecht, Netherlands. Retrieved from http:// www.surf.nl/ en/ knowledge-and-innovation/knowledgebase/ 2013/trend-report-open-educational-resources-2013.html

Neven, F., \& Duval, E. (2002). Reusable learning objects: A survey of LOM-based repositories. Proceedings of the tenth ACM international conference on Multimedia, 291-294. Retrieved from http:// hmdb.cs.kuleuven.be/ publications/ files/Lorsurvey.pdf

OECD (2007). Giving knowledge for free. The emergence of open educational resources. Retrieved from http:// www.oecd.org/ edu/ ceri/ 38654317.pdf

Pohl, K., Böckle, G., \&van der Linden, F. (2005). Software product line engineering. Berlin Heidelberg: Springer Verlag.

Rippel, M., Panchal, J . H., Schaefer, D., \& Mistree, F. (2009). Fostering collaborative learning and educational mass customization in a graduate level engineering design course. International J ournal of Engineering Education, 25(4), 729744 . 
Schuwer, R. (2013). Kwaliteitsvraagstukken voor OER in het Nederlandse hoger onderwijs (Quality problems with OER in Dutch Higher Education) (in Dutch). SURF, Utrecht. Retrieved from http:// www.surf.nl/binaries/content/assets/surf/nl/kennisbank/2013/rapport -kwaliteit-van-open-leermaterialen-07-11-2013.pdf

Shoham, Y. (2012). Packaged online courses (POCs). Retrieved from http:// robotics.stanford.edu/ shoham/ www\%20papers/ Higher\%20Educated \%20Guesses\%20-\%20Universities.pdf

Tseng, M., \&J iao, J . (2001). Mass customization. In G. Salvendy (Ed.), Handbook of industrial engineering (pp. 684-709). New York: Wiley.

Ulrich, K.T., \& Tung K. (1991). Fundamentals of product modularity. DE-Vol. 39, Issues in Design Manufacture Integration, ASME.

Universities UK (2011). Efficiency and effectiveness in higher education. London.

U.S. Department of Education, Office of Educational Technology (2010). Transforming American education: Learning powered by technology. Washington D.C. Retrieved from http:// www2.ed.gov/about/offices/list/os/technology/ netp.pdf

Valcke, M., Martens, R., \&Weges, H. (1997). Mercator. An integral system for realizing just in time learning, tailor made courses, demand-driven education and printing on demand (Mercator. Een integraal systeem voor het realiseren van just in time learning, tailor made courses, demand-driven education en printing on demand) (in Dutch). Landelijke dag studievaardigheden, Heerlen. Retrieved from http:// www.open.ou.nl/lds97/ mercator.htm

Yuen, K., \& Wong, A.J . (2013). Open educational resources in Hong Kong. In G Dhanarajan \&D. Porter (Eds.), Open educational resources: An Asian perspective (pp. 41-51). Vancouver: Commonwealth of Learning.

\section{Athabasca University $\mathbf{Z}$}

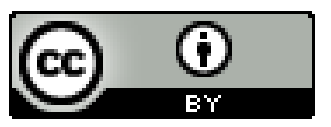

